Covered in: ERIH PLUS, HeinOnline, CEEOL, Index Copernicus, CrossRef, CrossCheck, J-GATE, Google Scholar, Ideas RePeC, Econpapers, Socionet, KVK, WorldCat.

2020, Volume 8, Issue 1, pages: 73-84 | doi: 10.18662/lumenlaw/8.1/38

\section{The Effects of Violence Against Women}

\section{Magdalena Roxana NECULA ${ }^{1}$}

${ }^{1}$ Pd.D., President of Iaşi Local Division of National College of Social Workers - Romania, Associated Professor at "Alexandru Ioan Cuza" University from Iaşi, Faculty of Philosophy and Social-Political Sciences and Faculty of Economics and Business Administration from Iaşi, Romania
Abstract: This paper is addressing a theoretical review of the violence against women, as reported and described by world health and human rights organizations, but also by women's advocacy and NGOs for women's rights. There were sketched the main definitions and framing of the acts of violence against girls and women, as well as the effects of violence against women, individually - on the physical, emotional, and mental health of the victim - and socially, in terms of longterm costs in providing support and specialized treatment to victims and their caregivers.

Keywords: violence against women, gender-based violence, physical violence, intimate partner violence, mental health, female victims.

How to cite: Necula, M. R. (2020). The Effects of Violence Against Women. Logos Universality Mentality Education Novelty: Law, 8(1), 73-84. doi:10.18662/lumenlaw/8.1/38 


\section{Introduction}

Violence against women is known as violence gender-based violence (Russo \& Pirlott, 2006) and sexual and gender violence (WHO, 2017). These forms of violence represent mainly or exclusively act of violence against women and girls. Manifested under the form of an offense generated by hate, violence against women is considered as a gender-based crime, as it is oriented specifically against the woman because she is a woman (Angelari, 1997, pp. 405-448; Gerstenfeld, 2013, p. 58; McPhail, 2003).

The context of this approach in this article is given by the results of one of the few studies concerning the violence against women, published in 2005 by World Health Organization. Numerous types of violence regarding women are often seen by women, when experienced, as being particularly shameful and as events that are private and should remain as such. Because of this lack of openness and sensitivity to the subject and due to the vulnerability that the abused women are experiencing on so many levels, violence in most cases remains under-reported. The existing data from the studies performed by WHO regarding the prevalence of such a violence is suggesting that, worldwide, there are a lot of women, maybe millions, who are suffering due to violence or living with the consequences of the abuse (García-Moreno \& Stöckl, 2013, p. 2; Ivlampie, 2018, pp. 79-85).

Globally, a study that has produced comparative data in both the urban and rural environments from 10 countries (Bangladesh, Samoa, Brazil, Serbia and Montenegro, Ethiopia, Japan, Peru, Namibia, Thailand and the United Republic of Tanzania), on a population with medium and very small income, was the multi-state study developed by the World Health Organization (WHO) regarding the violence against women. The study "used a standardized questionnaire and a standardized preparation of the implementation procedures in order to measure the prevalence of different forms of violence" (García-Moreno \& Stöckl, 2013, p. 3; WHO, 2005) within the population, especially partner violence. This multistate study performed by WHO interviewed over 24,000 women aged 15 and 49 years old. According to the results published in the research report from 2005, it was found that "the prevalence of physical and/or sexual violence of an intimate partner had a rate of $15 \%$ in Japan and approximately $70 \%$ in Ethiopia and Peru, reporting prevalence between 29 and 62\%" (GarcíaMoreno \& Stöckl, 2013, p. 3; WHO, 2005). The physical abuse of a partner at a certain moment in life, to people up to 49 years old, was reported to be between 13-61\% among the interviewed people in all the places of the study and the sexual abuse was between 6-59\%. The type of violence placed in the 
category of physical violence and sexual violence (or, in some cases, both), done by a non-partner, in any moment after the age of 15 , was reported to be 5.1 up to $64.6 \%$ among the interviewed people. Sexual violence of a nonpartner, in any moment after the age of 15 years old and up to 49 years old was reported to be $0.3-11.5 \%$ the interviewed people (García-Moreno \& Stöckl, 2013, p. 3; WHO, 2005).

The present paper is approaching violence against women at a theoretical level, as it is reported and described by worldwide health and human-rights organizations, but also by the feminist NGO's and advocacy organizations for women rights. There were targeted the main definitions and framings of the violence acts against women and girls, as well as the effects on an individual basis - the physical, emotional, and mental health of the victim - and on the social basis - expressed in long term costs due to the support and specific treatment of the victims and their parents or guardians.

\section{Types of the violence against women according to WHO, UNITED NATIONS and EU}

World Health Organization (WHO) had elaborated in 1997 a set of documents systematically describing the types of violence against women, based on the stages of the human development, creating a table of the types of VAW (Violence against Women).

Table 1. Types on violence against women in different stages of age development

STAGE

Ante-birth
The infantile
period

Childhood

\section{TYPE OF VIOLENCE}

\section{Selective sex abortion; effects of repeated beatings} during the pregnancy upon the fetus at birth (WHO, 1997);

Feminine "infanticide; physical, sexual and psychological abuse” (WHO, 1997);

Child marriage; women "genital mutilation; physical, sexual and psychological abuse; incest; child prostitution and pornography" (WHO, 1997); 
The adolescence and the adult period

Violence in meetings and courtesy (for example, throwing acid and rape); economical forced sex (for example, schoolgirls having sex with "sugar daddies" in exchange of tuition fees); "incest; sexual abuse at workplace; rape; sexual harassment; forced prostitution and pornography; trafficking women; partner violence; marital rape" (WHO, 1997); partner homicide; psychological abuse; abuse of disabled women; forced pregnancy; abuse and homicide for dowry;

Forced "suicide" or widow homicide due to

The third age economical reasons; sexual, physical and psychological abuse.

Source: WHO (1997)

The General Meeting of United Nations had adopted in 1993, the Declaration on the Elimination of Violence against Women, bringing specific definitions to the phenomena. Therefore, the Organization of United Nations is defining violence against women as "any act of genderbased violence that results in, or is likely to result in, physical, sexual or psychological harm or suffering to women, including threats of such acts, coercion or arbitrary deprivation of liberty, whether occurring in public or in private life" (UN, 1993, p. 2; WHO, 2017).

The Declaration of the United Nations is stating that violence against women is a manifestation throughout the history of the unequal relationships of power between men and women, a social mechanism which is forcing women in a subordinate position in comparison with men (UN, 1993).

The categorization of the types of violence against women cannot be an exhaustive action, as both the Organization of United Nations (2006), and the Council of Europe are realizing typologies of such acts of violence against women, without limiting the possibility to frame later discovered new forms.

Thus, in the "Recommendation Rec (2002)5 of the Committee of Ministers towards the member states on the protection of women against violence" (Council of Europe and Committee of Ministers, 2002), the Council of Europe is bringing completions to the typology sustained by the United Nations since 1993, and stipulates that VAW includes, but does not limits the following Recommendations Rec (2002)5. 
a) violence within the family or the internal unit, including, among others, physical and psychical aggression, emotional and psychological abuse, rape and sexual abuse, incest, spouse rape, usual and occasional partners rape, crimes committed in the name of honor, genital and sexual mutilation of women and other harmful traditional practices against women, such as forced marriages;

b) "violence appearing within the general community, including, among others, rape, sexual abuse, sexual harassment and intimidation at work, in institutions or elsewhere, trafficking of women for sexual and economical exploitation purposes and sexual tourism" (Council of Europe and Committee of Ministers, 2002);

c) violence committed by the state or its employees;

d) "violation of human rights and of the women in armed conflicts, especially hostile takeover, forced displacement, systematic rape, sexual slavery, forced pregnancy and trafficking for sexual and economical exploitation purposes" (Council of Europe and Committee of Ministers, 2002).

\section{Effects of violence in the private and public life of women}

In the Resolution of World Medical Association (WMA) on the violence against women, WMA is sustaining that the definitions of violence are varying, but it is imperative for all forms of violence that take place to be recognized by the policy makers, in order to intervene in their elimination. Violence against women and girls is including violence within the family, community and violence committed by the state. It stands to reason the huge impact of this phenomenon upon the victims and their parents or guardians, being extended to the community where they live in. Globally are identified numerous "justifications" or excuses attributed to violence. Most of them are deriving from the cultural area; in cultural and societal terms, these excuses are including traditions, beliefs, customs, values and religion. In addition, the traditional power difference between men and women is a major cause, even if it is addressed less often (WHO, 2010).

Despite the active involvement of numerous activists, NGO's, advocacy actions, the problem of violence against women remains "one of the most widespread forms of human rights violation worldwide" (Fried, 2003, p. 91). Violence against women can appear both in the public sphere as well as in the private one, in any moment of life and is affecting not only the victim directly, but also the community it belongs to. This phenomenon 
is impeding women to fully contribute to the social, economical and political development of their communities. (Fried, 2003)

The consequences of violence against women are manifesting directly upon the physical health, followed by a deterioration of the mental and emotional health.

\subsection{Effects of the violence in intimate relationships, upon the health of the woman and her child}

World Health Organization (2017) is stating a series of consequences identified in the cases of violence against women, within the couple, intimate relationship, with impact both on the abused woman as well as upon the children, witness victims or direct victims. Sexual violence is causing serious problems on short and long term against women, at all levels: physical, mental, sexual and reproductive. The victims can be murdered or as a consequence of the offense can commit suicide. Violence in intimate relationships can provoke lesions, $42 \%$ of the women who are confronted with the violence of their intimate partner are saying that they have been injured by the violent acts of their partner.

Violence in intimate relationships can lead to unwanted pregnancies, induced abortions, gynecological complications and STDs (sexually transmitted diseases), including HIV. An analysis from 2013 established that the physically or sexually abused women had a 1.5 greater likelihood to acquire a STD and HIV, in comparison to the women who haven't had violent partners (WHO, 2017).

The violence of a violent partner during pregnancy is increasing the probability of a spontaneous abortion, birth that can cause death to the mother, prenatal birth and low birth weight babies. The same study from 2013 had shown that the women who have endured the violence from an intimate partner have had $16 \%$ more chances to experience a miscarriage and $41 \%$ probability to a prenatal birth (WHO, 2013).

"These forms of violence can lead to depression, post-traumatic stress and anxiety disorders, sleep difficulties, eating disorders and suicide attempts" (WHO, 2013). The analysis from 2013 had established that women who say that they have been the victim of the violence induced by an intimate partner were twice more susceptible to suffer from depression and to experience alcohol consumption problems (WHO, 2013).

The effects upon health can include as well headaches, limited mobility, back and abdominal pains, gastrointestinal disorders and a low level of health status. 
Sexual violence, mostly since childhood, can be the reason for future to drug consumption and alcohol abuse and to potentially hazardous sexual behaviors later on in life (WHO, 2013, 2017).

In what concerns the relationships within the family, in the relation parent-child, the children raised in families where they experience violence, can suffer series of behavioral and emotional troubles and can become, themselves, subjects of the abuse (Modi et al., 2014). Being witnesses of violence within the family can cause the perpetuation of violence itself in the future behavior of the child. In the same time, the violence of the violent partner was associated with a higher incidence of cases of infantile and small child mortality and morbidity - causing diarrheic diseases or malnutrition (WHO, 2017).

At mental and emotional health level, the victims of the physical or sexual violence can suffer in the long term different disturbances such as: post-traumatic stress disorder - a trouble associated with a traumatism or a chocking or frightening experience, such as sexual aggression or physical abuse (Delara, 2016).

\subsection{Effects on the physical health of the woman}

The effect of violence against women is manifested both immediately, as well as on the long run. At the level of violence against women in intimate relationships and domestic violence, according to a study carried on a population of approximately 400 Swedish adult women, the health issues were 11 times more frequent in the group of women who were the victims of violence during childhood, than the control group and 7 times more often met in a group of women who have experienced violence in their teens, in comparison with the control group (Krantz \& Ostergren, 2000; Popa, 2009). Another study from the same area of interest is showing that more than $3 / 4$ of the study subjects - out of 99 women battered by their partners - have suffered at least one brain lesion caused by their partners and approximately half of them have experienced multiple brain injuries (Valera \& Berenbaum, 2003).

The physical illnesses frequently affecting the women victims of intimate relationships violence, and not only, are numerous and with consequences triggered in time, most of the times being associated with mental and emotional disorder: thoracic and abdominal disturbances, swellings, scratching, eye and/or facial lesions, the chronic pain syndrome, incapacity, fractures, gastro-intestinal dysfunctions, the irritable bowel syndrome, muscular pain, headaches, migraines etc. (Popa, 2009). 
The direct consequence of the violence upon health depends on the nature of the act For example female genital mutilation can kill the woman during the deed, or gradually, and can lead to difficulties in eliminating the matters produced by the body, including the menses, and can result in fertility complications. The same inhuman act of genital mutilation is supporting and making stronger the ideological concept according to which women are the possessions of men, and, in an abusive manner, they can control their sexuality. In the same register of sexual violence, the gang rape can lead, from an anatomical point of view, to potential gynecological, urological and intestinal difficulties on long term, including the development of fistulae and incontinency, which can further diminish the social support for the abused woman (WHO, 2010). At the level of the violent intimate relationship the following illnesses may occur at any time: gynecological disorders, sterility, acute/chronic pelvic or local inflammation, endometriosis, birth complications, sexual diseases, HIV/AIDS, spontaneous/caused miscarriages, unwanted pregnancies, premature birth, prematurity/dystrophy, amenorrhea and menstruation abnormalities etc. (Campbell, 2002; Popa, 2009).

\subsection{Effects on the mental health of the woman}

One of the most common and frequently reported forms of violence against women is precisely the violence in intimate relationships. The sexual abuse is causing deep wounds, on long term, on physical, emotional and mental level. The abused women (Lența \& Cormoş, 2017, pp. 57-65) are often living with unbearable mental sequelae including the post-traumatic stress syndrome, anxiety disorders and depression, suicidal thoughts, abusive consumption of substances and dissociative disturbances and somatoform disorders. Nevertheless, to date, psychiatry and psychotherapy have neglected on large scale violence as a factor of influence upon the mental health (García-Moreno \& Riecher-Rössler, 2013).

Within a multi-stately study of WHO regarding the women health and domestic violence against women (WHO, n.d.), the mental health was evaluated with the help of a self-reported questionnaire with 20 questions (SRQ-20), developed by WHO as a screening instrument for the emotional distress. This instrument was integrated in the health section of the questionnaire. The respondents were asked if they have encountered, during the course of all 4 weeks before the interview, as series of symptoms associated with the emotional distress, such as crying, incapacity to enjoy life, tiredness and thoughts about ending life. The study carried on in 10 states, on a number of 24,000 respondents, had indicated that in all the 
locations of the study, the average score for the women who suffered abuses was significantly higher that the women who were not abused. As well, the women were asked about their suicidal thoughts and attempts, at any moment of their lives. Both in the case of the women who have reported thoughts of taking their own lives, depending on their share of violence experienced due to an intimate partner, as well as in the case of the women with suicidal thoughts who have reported that had intended, at a certain moment, to kill themselves due to violence, the percentage is much higher with respect to the percentage of women who have never experienced any kind of violence (WHO, n.d.).

The correlation of the idea and the suicidal behavior with the violence of the intimate partner, as it resulted from WHO study, was found again in other studies achieved in both developing countries as well as in industrialized ones (Fischbach \& Herbert, 1997; Muelleman \& Lenaghan, 1998). Due to a lack of data base which can keep track of the number of suicides among women, the association of violence in intimate relationships with the suicidal behavior can be underrated. Rather other "mental health issues such as depression and anxiety disorders in women are widely recognized as important sequelae of intimate partner violence worldwide" (Jewkes et al., 2002).

\subsection{Effects on the social life of the woman}

At the level of its manifestation, on social and community plan of this phenomenon, there were noticed huge social and economical costs provoked by the intimate partner violence and the sexual violence. The victims are experiencing suffering on long term, and with them, the society who is supporting in their recuperation is deploying considerable efforts, both financial and social, as well as aiming to the renovation of the mentality. The women victims can feel isolated, are incapable to perform work duties and later are losing their sources of income, no longer participate to ordinary activities and lose or have limited capacity to take care of themselves and their own children (WHO, 2017).

\section{Conclusions}

Violence against women is a dynamic, developmental phenomenon, favored by a series of factors such as education, culture, ideologies sustained and perpetuated throughout history, $\mathrm{n}$ individual and collective mentality printed by the normality of the discrimination and the gender-based inconsideration. 
Violence against women or gender-based violence was approached in this paper from a theoretical summarized perspective, limited by the space of the article, as some relevant aspects were reviewed in order to develop some actions to stop the phenomenon.

The starting point in the identification of the defining aspects of this social mechanism of women oppression was the incorporated vision of the worldwide organizations from the field of human rights and health - World Health Organization, World Medical Association, United Nations and the European Council.

\section{References}

Angelari, M. (1997). Hate crime statutes: A promising tool for fighting violence against women. In K. J. Maschke, Pornography, sex work, and hate speech (pp. 405-448). Taylor and Francis.

Campbell, J. C. (2002). Health consequences of intimate partner violence. The Lancet, 359, 1331-1336. https://doi.org/10.1016/S0140-6736(02)08336-8

Council of Europe, Committee of Ministers. (2002). Recommendation (2002)5 of the Committee of Ministers to member states on the protection of women against violence. https://search.coe.int/cm/Pages/result details.aspx?ObjectID $=09000016$ $\underline{805 \mathrm{e} 2612}$

Delara, M. (2016). Mental health consequences and risk factors of physical intimate partner violence. Mental Health in Family Medicine; 12, 119-125. https:// www.mhfmjournal.com/old/open-access/mental-health-consequencesand-risk-factors-of-physical-intimate-partner-violence.pdf

Fischbach, R. L., \& Herbert, B. (1997). Domestic violence and mental health: correlates and conundrums within and across cultures. Social Science and Medicine, 45(8), 1161-1176. https://doi.org/10.1016/s0277-9536(97)00022-1

Fried, S. T. (2003). Violence against women. Health and Human Rights Journal, 6(2), 88-111. https://doi.org/10.2307/4065431

García-Moreno, C., \& Riecher-Rössler, A. (Eds.). (2013). Violence against women and mental health. Key issues mental health. Karger.

García-Moreno, C., Stöckl, H. (2013).Violence against women, its prevalence and health consequences. In C. García-Moreno \& A. Riecher-Rössler (Eds.), Violence against women and mental health. Key issues mental health (pp. 1-11). Karger.

Gerstenfeld, P. B. (2013). Hate crimes: causes, controls, and controversies. Sage.

Ivlampie, I. (2018) Identity and alterity in the primitive era of globalization. Postmodern Openings, 9(2), 79-85. http://dx.doi.org/10.18662/po/19 
Jewkes, R., Sen, P., \& Garcia-Moreno, C. (2002). Sexual violence. In E. G. Krug E.G. L. L. Dahlberg, J. A. Mercy, A. B. Zwi \& R. Lozano (Eds.), World report on violence and health. World Health Organization.

Krantz, G. \& Ostergren, P. (2000). The association between violence, victimization and common symptoms in Swedish women. Journal of Epidemiology and Community Health, 54(11), 815-821. https://doi.org/10.1136/jech.54.11.815

Lența, O., \& Cormoş, V. C. (2017). Aggression and violence, corrosive factors of humanity. Postmodern Openings, 8(1), 57-65. https://doi.org/10.18662/po/ 2017.0801.05

McPhail, B. (2003). Gender-bias hate crimes: A review. In B. Perry (Ed.), Hate and bias crime: aAreader (p. 271). Routledge.

Modi, M. N., Palmer, S., \& Armstrong, A. (2014). The role of violence against women act in addressing intimate partner violence: A public health issue. Journal of Women's Health, 23(3), 253-259. https://doi.org/10.1089/ jwh.2013.4387

Muelleman, R. L., Lenaghan, P.A., \& Pakieser R. A. (1998). Non-battering presentations to the ED of women in physically abusive relationships. The American Journal of Emergency Medicine, 16(2), 128-131. https://doi.org/ $\underline{10.1016 / \mathrm{s} 0735-6757(98) 90028-6}$

Popa, M. S. (2009). Domestic violence and its consequences on health, Management in Health, 13(3), 11-14. https://doi.org/10.5233/mih.2009.0019

Russo, N. F., \& Pirlott, A. (2006). Gender-based violence: concepts, methods, and findings. Annals of the New York Academy of Sciences, 1087, 178-205. https://doi.org/10.1196/annals.1385.024

United Nations General Assembly (UN). (2006). In-depth study on all forms of violence against women. Report of the Secretary-General A/61/122/Add. https://www.un.org/womenwatch/daw/vaw/SGstudyvaw.htm

United Nations General Assembly. (2013). A/RES/48/104 - Declaration on the Elimination of Violence against Women. http://www.un-documents.net/ a48r104.htm

Valera, E. M., \& Berenbaum, H. (2003). Brain injury in battered women. Journal of Consulting and Clinical Psychology, 71(4), 797- 804. https://doi.org/10.1037/ 0022-006x.71.4.797

World Health Organization (WHO), Department of Reproductive Health and Research, London School of Hygiene and Tropical Medicine, South African Medical Research Council (2013). Global and regional estimates of violence against women, Prevalence and health effects of intimate partner violence and non-partner sexual violence. https://apps.who.int/iris/ bitstream/handle/10665/85239/9789241564625_eng.pdf;jsessionid=D28 FE0DA18B11097C9AE3006E9F64101?sequence $=1$ 
World Health Organization (WHO). (1997). Violence against women: Definition and scope of the problem. https://www.who.int/gender/violence/v4.pdf

World Health Organization (WHO). (2005). WHO multi-country study on women's health and domestic violence against women. Report - Initial results on prevalence, health outcomes and women's responses. https://www.who.int/reproductivehealth/publications/violence/2415935 $\underline{\text { 8X/en/ }}$

World Health Organization (WHO). (2010). WMA Resolution on violence against women and girls. https://www.wma.net/wp-content/uploads/2017/02/ Violence against Women-Oct2010.pdf

World Health Organization (WHO). (2017, November 29). Violence against women. https://www.who.int/news-room/fact-sheets/detail/violenceagainst-women

World Health Organization (WHO). (n.d.). Sexual and gender-based violence. https://www.who.int/hac/techguidance/pht/SGBV/en/ 